\title{
POLÍTICA PÚBLICA E COLABORAÇÃO INTERGOVERNAMENTAL: ANALISANDO O CASO DO PNAIC EM RECIFE
}

\author{
POLÍTICA PÚBLICA Y COLABORACIÓN INTERGUBERNAMENTAL: ANALIZANDO \\ EL CASO DEL PNAIC EN RECIFE
}

\author{
PUBLIC POLICY AND INTERGOVERNMENTAL COLLABORATION: ANALYZING \\ THE CASE OF PNAIC IN RECIFE
}

\author{
Jéssica Santos do NASCIMENTO ${ }^{1}$ \\ Ana Lúcia Felix dos SANTOS ${ }^{2}$
}

RESUMO: O trabalho trata sobre o Pacto Nacional pela Alfabetização na Idade Certa (Pnaic) e teve como objetivo analisar como se deu o processo de implementação desse Programa na cidade do Recife, tomando como referente o regime de colaboração e o poder local na gestão desse programa educacional. A metodologia foi do tipo qualitativa e utilizou como procedimentos de coleta de dados entrevistas semiestruturadas e análise de documentos. Os dados revelaram que a cooperação seguiu o disposto na legislação própria do Pnaic, que define as ações que são de responsabilidade de cada instância administrativa envolvida. No entanto, foi possível observar lacunas na implementação da política, seja por fragilidades locais, seja pela própria dinâmica de ação da política.

Palavras-chave: Política educacional. Regime de colaboração. Pacto Nacional pela Alfabetização na Idade Certa (Pnaic). Recife.

RESUMEN: El trabajo trata sobre el Pacto Nacional por la Alfabetización en la Edad Cierta (Pnaic), y ha tenido objetivo analizar cómo se dio el proceso de implementación de ese Programa en la ciudad de Recife, teniendo como referente el régimen de colaboración y el poder local en la gestión de este programa educativo. La metodología fue del tipo cualitativo y utilizó como procedimientos de recolección de datos entrevistas semiestructuradas y análisis de documentos. Los datos revelaron que la cooperación siguió lo dispuesto en la legislación propia del PNAIC, que define las acciones que son de responsabilidad de cada instancia administrativa involucrada. Sin embargo, fue posible observar lagunas en la implementación de la política, sucede por fragilidades locales, o por la propia dinámica de acción de la política.

PALABRAS CLAVE: Política educativa. Régimen de colaboración. Pacto Nacional por la Alfabetización en la Edad Cierta (Pnaic). Recife.

\footnotetext{
${ }^{1}$ Universidade Federal de Pernambuco (UFPE), Jaboatão dos Guararapes - PE - Brasil. Mestre em Educação pela UFPE. Professora da Rede Municipal de Jaboatão dos Guararapes. ORCID: <https://orcid.org/0000-0002-36414673>.E-mail: jessik.cdf@gmail.com

${ }^{2}$ Universidade Federal de Pernambuco (UFPE), Jaboatão dos Guararapes - PE - Brasil. Doutora em Educação pela UFPE. Professora do Centro de Educação e do Programa de Pós-graduação em Educação da UFPE. ORCID: <http://orcid.org/0000-0002-1040-2156>. E-mail: analufelix@ gmail.com
}

RPGE- Revista on line de Política e Gestão Educacional, Araraquara, v. 23, n. 2, p. 370-387, maio/ago., 2019. E-ISSN:1519-9029. 
ABSTRACT: The paper deals with the National Pact for Literacy in the Right Age (PNAIC), and had as objective to analyze how the process of implementation of this Program in the city of Recife took place, taking as reference the collaboration regime and local power in the management of this educational program. The methodology applied was the qualitative type and semi structured interviews and document analysis were used as data collection procedures. The data showed that the cooperation followed the provisions of the specific legislation of the PNAIC, which defines the actions that are the responsibility of each administrative body involved. However, it was possible to observe gaps in the implementation of the policy, either by local weaknesses or by the very dynamics of policy action.

KEYWORDS: Educational policy. Regime of collaboration. National Pact for Literacy in the Right Age (PNAIC). Recife.

\section{Introdução}

O presente trabalho trata sobre o Pacto Nacional pela Alfabetização na Idade Certa (Pnaic) e buscou olhar para esse Programa a partir da perspectiva da gestão municipal, do regime de colaboração e do poder local. O Pnaic tem por objetivo assegurar que todas as crianças estejam alfabetizadas até os oito anos de idade, ao final do $3^{\circ}$ ano do Ensino Fundamental, e para isso propõe uma ação colaborativa entre as instâncias governamentais envolvidas no processo.

Desse modo, a pesquisa teve como objetivo analisar como se deu o processo de implementação do Pnaic, na cidade do Recife, considerando o regime de colaboração e o poder local na gestão desse programa educacional. Partiu-se da hipótese de que o regime de colaboração atuou como elemento importante no desafio à implementação do Programa no município, colocando-se como elemento de contribuição para a melhoria da qualidade da educação e dos processos de alfabetização.

O Pnaic é um dos programas que parte da premissa de que a garantia da educação depende de um compromisso que envolve o Ministério da Educação (MEC), as secretarias estaduais, distrital e municipais de educação. Assim, o Programa se caracteriza por incentivar estados e municípios a tornar efetiva a alfabetização das crianças com base na justificativa de que "Muitas crianças brasileiras concluem o ciclo destinado à sua alfabetização sem estarem plenamente alfabetizadas" (BRASIL, 2012a, p. 04).

O compromisso é reforçado pela inserção do termo pacto na nomenclatura do programa, no sentido de assimilarmos que esse termo esclarece a estrutura política na oferta do programa a partir, necessariamente, da pactuação, ou seja, exige-se a colaboração entre os entes federados na sua efetivação. Desse modo, o referido termo aparece como um guia de interesse nesta 
pesquisa, já que é de nosso propósito analisar o programa do ponto de vista de sua materialização enquanto política que exige cooperação entre os entes federados. Na verdade, compreendemos o termo pacto para além de um simples contrato por adesão; ele nos sugere um princípio norteador para os entes federados, impulsionando-os fundamentalmente para o processo de andamento e da implementação do Programa.

Elegemos Recife como campo de pesquisa, que é um município que tem desenvolvido ações para o fortalecimento da educação municipal no âmbito das suas responsabilidades com a educação básica e aderiu ao Pnaic no ano de 2012.

A pesquisa, de cunho qualitativa, focou no processo de implementação, uma vez que, como Perez (2010) coloca, acreditamos que o contexto de formulação e implementação deve se articular sempre, compreendendo que uma política é colocada em ação por fases e estágios não estanques, mas dinâmicos (PEREZ, 2010).

A técnica de coleta de dados envolveu observação sistemática, levantamento e análise de documentos (legislação específica do Pnaic) e aplicação de entrevistas semiestruturadas. As entrevistas foram aplicadas a diferentes sujeitos envolvidos com o Pnaic: 2 representantes do MEC; 3 representantes da UFPE, 2 representantes locais (municipais), 1 orientador de estudos, 2 professoras alfabetizadoras. Para análise, aplicamos a técnica de análise de conteúdo de Bardin (1989).

\section{Políticas públicas, políticas educacionais e o regime de colaboração: contexto de surgimento do Pnaic}

Ao tratarmos de um programa educacional, inserimos o mesmo no cômputo das políticas de corte social; neste caso, políticas atreladas às decisões que o poder público toma em relação à educação. Considerando a educação um fenômeno de grande complexidade, estamos aqui nos referindo à educação escolarizada.

Se "políticas públicas" é tudo aquilo que um governo faz ou deixa de fazer, políticas públicas educacionais é tudo aquilo que um governo faz ou deixa de fazer em educação. Porém, educação é um conceito muito amplo para se tratar das políticas educacionais. Isso quer dizer que políticas educacionais é um foco mais específico do tratamento da educação, que em geral se aplica às questões escolares. Em outras palavras, pode-se dizer que políticas públicas educacionais dizem respeito à educação escolar (OLIVEIRA, 2010, p. 4).

Aqui, no Brasil, para entender e analisar as políticas educacionais é necessário focá-las no âmbito da organização federalista que marca o nosso Estado. É ainda, por esse prisma, que 
podemos compreender a questão do regime de colaboração. Conceitos importantes para a análise do nosso objeto de estudo. O federalismo como forma de organização políticoadministrativa pode ser aplicado de diversas formas. No nosso caso, a Constituição Federal (CF) (1988) optou pelo modelo federalista de cooperação, que:

Busca um equilíbrio de poderes entre a União e os Estados membros, estabelecendo laço de colaboração na distribuição das múltiplas competências por meio de atividades planejadas e articuladas entre si, objetivando fins comuns. Esse federalismo político é o registro jurídico de nossa atual constituição (CUNHA; COSTA; ARAÚJO, 2010, p. 18).

Como se pode destacar, no Brasil, o regime federalista é o cooperativo, dado o Art. 23 da CF (1988), que no Parágrafo único define: "Leis complementares fixarão normas para a cooperação entre a União e os Estados, o Distrito Federal e os Municípios, tendo em vista o equilíbrio do desenvolvimento e do bem-estar em âmbito nacional”. No que tange as políticas para educação, esse modelo federalista implica responsabilidades de cada ente federado por níveis e etapas de ensino e a necessidade de cooperação para a ofertá-los. Sendo que a educação básica será acobertada pelos estados e pelos municípios, com a colaboração e complementariedade da União quando necessário. A Lei de Diretrizes e Bases da Educação, no 9.394, no Art. 11, inciso V, que os municípios devem oferecer a educação infantil e, com prioridade, o Ensino Fundamental. "Oferecer a educação infantil em creches e pré-escolas, e, com prioridade, o Ensino Fundamental" (BRASIL, 1996).

Vê-se que, apesar dos municípios terem sido incorporados recentemente como entes e de possuírem menores receitas, eles desde o processo de municipalização vêm absorvendo alunos de todo o Ensino Fundamental. Como bem abordado em Cunha, Costa e Araújo (2010, p. 19), após 1988, “importantes tarefas, antes assumidas pela União ou pelo Estado, passaram a ser de responsabilidade do município", o que gerou grandes desafios para esses entes federados

Cabe ressaltar que o federalismo brasileiro mantém estreitas relações com o poder local, possibilitando um protagonismo dos diversos municípios, já que, em princípio, esses gozam de autonomia (ANDRADE; GOMES, 2012). Nesta perspectiva, parte-se de uma concepção de gestão sistêmica, em que há uma proposta de unidade dentro desse novo federalismo, precisando sempre do fortalecimento do regime de colaboração, que, para Andrade (2013, p. 02),

Estabelecida a corresponsabilidade entre Estados, Municípios e União, o que se constata é a indefinição do que cabe a cada instância de poder, sobretudo quando se refere à constituição de instrumentos que explicitem os papéis 
específicos de cada esfera administrativa, assim como as ações que serão pactuadas entre os sistemas de educação com o fim de atingir o atendimento de toda a educação básica no âmbito municipal.

É nesse contexto federado que a União tem exercido sua função de estabelecer e coordenar políticas educacionais para a melhoria da qualidade do ensino em todos os âmbitos da nossa educação. Assim, o Pnaic surge nesse cenário, com ações que envolvem estados e municípios, já que estes últimos têm responsabilidade direta sobre o oferecimento do Ensino Fundamental.

Ao instituir o Pnaic, o MEC faz referência ao Decreto $\mathrm{n}^{\circ}$ 6.094, de 24 de abril de 2007, que zela pela "implementação do Plano de Metas Compromisso Todos pela Educação, pela União Federal, em regime de colaboração com Municípios, Distrito Federal e Estados", revelando ações coordenadas em um plano mais amplo no que diz respeito à melhoria da qualidade da educação e ações de colaboração entre os entes federados. Assim, nossa investigação parte da ideia do pressuposto do compromisso e da colaboração entre os entes federados prevista na Portaria, e isso subentende a relevância dessa pesquisa no contexto local, focando especificamente a implementação desse programa em um município.

Discutir políticas em suas relações com os municípios é também colocar em relevo a questão do poder local e o debate sobre a participação de grupos minoritários nas questões políticas e sociais. O poder local pode ser entendido como capacidade de reação organizada dos membros de um local, bairro, comunidade ou município, unidos por um sentimento de pertencimento e de reconhecimento identitário, frente às tendências de deliberações imperativas oriundas de poderes mais centralizadores. Sendo, então, reconhecida essa atuação do grupo do poder local, ela é capaz de provocar a admissão de suas especificidades como elemento importante na formulação de políticas públicas (SANTOS, 2002; DOWBOR, 2008).

Isto significa termos espaços cada vez mais permeados por expressões participativas democráticas decidindo sobre o rumo das próprias vidas dos sujeitos pertencentes a estes espaços, o que também fortalece princípios democráticos de inserção dos diferentes indivíduos na decisão da política local. Assim, é possível buscar analisar até que ponto o poder local tem feito intervenções em políticas de corte nacional.

A relevância da discussão sobre o local também emerge em meio ao debate sobre os processos de globalização. Para Santos (2002, p. 75), quando se trata da globalização, esperase que o local ocorra pela "transformação contra-hegemônica, que consiste na construção do multiculturalismo emancipatório, ou seja, na construção democrática das regras de reconhecimento recíproco entre identidades e entre culturas distintas”. Percebe-se que, quando 
esse autor se refere à globalização, ele também ressalta, por contraposição, a valorização do conjunto de símbolos dos indivíduos locais balizado por um sentimento de pertencimento comum.

$\mathrm{Na}$ nossa investigação, levamos em consideração as especificidades do poder local acima debatidas, mas também reforçamos que “[...], trata-se, portanto, de um esforço do município sobre si mesmo" (DOWBOR, 2008, p. 79-80). É nesse contexto que optamos por realizar esta pesquisa tomando como campo empírico a cidade do Recife, uma capital nordestina. É nossa intenção investigar a relação entre o regime de colaboração e as prerrogativas do poder local para o êxito de uma política gestada em âmbito nacional.

\section{O Pnaic: uma política com necessidade de colaboração}

É no contexto das ações de colaboração no bojo do estado federado que o governo federal cria o Programa Nacional pela Alfabetização na Idade Certa (Pnaic), um programa a ser executado a partir de um compromisso formal assumido pelos entes federados (governo federal, Distrito Federal, estados e municípios).

Ele se constitui por uma rede de formação cujo objetivo final consiste na formação de professores alfabetizadores das redes pactuadas. Suas ações estão distribuídas em quatro eixos: Formação continuada presencial para os professores alfabetizadores e seus orientadores de estudo; Materiais didáticos, obras literárias, obras de apoio pedagógico, jogos e tecnologias educacionais; Avaliações sistemáticas; Gestão, mobilização e controle social.

O primeiro eixo é o principal: Formação continuada presencial para os professores alfabetizadores e seus orientadores de estudo. Os professores alfabetizadores frequentam um curso presencial conduzido pelos orientadores de estudo. Este curso tem a duração de 2 anos, com uma carga horária de 120 horas por ano. Baseado no programa Pró-Letramento, sua metodologia propõe estudos e atividades práticas. A formação das turmas de orientadores de estudos corresponderia a 25 (vinte e cinco) indivíduos, podendo chegar a 34 (trinta e quatro), atendidos por uma Instituição de Ensino Superior (IES); cada turma de orientadores de estudos conteria um formador, incumbido por formar os cursistas. Ainda é importante destacar o papel das IES neste processo formativo. Segundo a Portaria $n^{\circ}$ 867, de julho de 2012, Art. 12, principalmente, caberá às IES: "I - realizar a gestão acadêmica e pedagógica do curso de formação" (BRASIL, 2012b). 
No eixo Materiais didáticos, obras literárias, obras de apoio pedagógico, jogos e tecnologias educacionais, o MEC distribui os materiais didáticos para as formações dos professores alfabetizadores e manda materiais para as escolas que estão envolvidas. Os materiais são: Livros didáticos (entregues pelo Programa Nacional do Livro Didático (PNLD)) e respectivos manuais do professor; Obras pedagógicas complementares aos livros didáticos e acervos de dicionários de Língua Portuguesa (também distribuídos pelo PNLD); Jogos pedagógicos de apoio à alfabetização; Obras de referência, de literatura e de pesquisa (entregues pelo Programa Nacional Biblioteca da Escola (PNBE)); Obras de apoio pedagógico aos professores; Jogos e softwares de apoio à alfabetização.

O eixo de avaliação do Pnaic tem referência na Provinha Brasil, aplicada no início e final do segundo ano e no terceiro ano; finalizando o Ciclo de Alfabetização, o MEC instituiu a Avaliação Nacional da Alfabetização (ANA). Esta tinha a finalidade de produzir indicadores que contribuíssem para o processo de alfabetização nas escolas públicas brasileiras.

Já o Eixo Gestão, mobilização e controle social, possui a seguinte organização: um Comitê Gestor Nacional e uma Coordenação Institucional em cada estado e no Distrito Federal, composto por diversas entidades, com atribuições estratégicas e de mobilização em torno dos objetivos do Pacto; uma Coordenação Estadual, responsável pela implementação e monitoramento das ações em sua rede e pelo apoio à implementação nos municípios; e uma Coordenação Municipal, responsável pela implementação e monitoramento das ações na sua rede.

Vejamos as responsabilidades da União e dos municípios na implementação do Pnaic no que diz respeito à formação de professores e material didático (BRASIL, 2012b):

Art. 11. Caberá ao MEC:

[...] IV - promover, em parceria com as Instituições de Ensino Superior (IES), a formação dos orientadores de estudo e dos professores alfabetizadores nas redes de ensino que aderirem às ações do Pacto; $\mathrm{V}$ - conceder bolsas de apoio para incentivar a participação dos orientadores de estudo e dos professores alfabetizadores nas atividades de formação nas redes de ensino que aderirem às ações do Pacto; VI - fornecer os materiais didáticos, literários, jogos e tecnologias previstos nos artigos $6^{\circ}, 7^{\circ}$ e $8^{\circ}$ desta Portaria, nas redes de ensino que aderirem às ações do Pacto; VII - fomentar as ações de mobilização e de gestão.

Art. 14. Caberá aos Municípios:

[...] IV - gerenciar e monitorar a implementação das ações do Pacto em sua rede; V - designar coordenador(es) para se dedicar(em) às ações do Pacto e alocar equipe necessária para a sua gestão, inclusive em suas unidades regionais, se houver; VI - indicar os orientadores de estudo de sua rede de ensino e custear o seu deslocamento e a sua hospedagem para os eventos de formação; VII - fomentar e garantir a participação dos professores 
alfabetizadores de sua rede de ensino nas atividades de formação, sem prejuízo da carga-horária em sala de aula, custeando o deslocamento e a hospedagem, sempre que necessário; VIII - monitorar, em colaboração com o MEC, a aplicação da Provinha Brasil e da avaliação externa, a entrega e o uso dos materiais de apoio à alfabetização previstos nesta Portaria; IX - disponibilizar assistência técnica às escolas com maiores dificuldades na implementação das ações do Pacto e na obtenção de resultados positivos de alfabetização [...].

As ações desenvolvidas pelo Pnaic são pautadas num compromisso decisivo em prol da alfabetização das crianças, o que reverbera na democratização da educação de qualidade no nosso país. A proposta do Pnaic foi apresentada aos estados e municípios e sua elaboração foi comparada ao Programa de Alfabetização na Idade Certa (Paic), do Ceará (SANTOS, 2015), considerada uma das influências para o surgimento do Pacto para além do Pró-Letramento. Santos (2015) apresenta um estranhamento quanto à falta de clareza dessa relação na origem do Pnaic. Na verdade, a autora reitera "a estranheza que lhe causa a ausência dessa referência nos documentos, bem como a necessidade de investigação do porquê dessa falta" (Ibid., p. 61).

A decisão pelo Pnaic como novo programa foi seguida de um processo de sensibilização para os estados e municípios entenderem melhor a proposta e, posteriormente, da abertura do SisPacto ${ }^{3}$ :

Depois dessa sensibilização, a gente abriu um sistema, que foi o SisPacto. Foi um trabalho construir porque tinha, vamos dizer assim, de ser capaz de agregar os municípios, eles se reconhecerem, na hora que eles entrarem, que aderiram o programa. Então na medida em que o município aderiu, estava assumindo as responsabilidades (Representante do MEC 1).

Além da articulação entre os entes, ainda nos primeiros contatos com estados e municípios, verificamos que houve uma parceria relevante, com o Conselho Nacional de Secretários da Educação (Censed) e com a União Nacional dos Dirigentes Municipais de Educação (Undime), no percurso inicial do Pnaic, vista como um elemento importante para a Representante do MEC e também para a Representante da universidade:

A gente convidava Undimes e secretarias municipais, então a gente começava com uma reunião com elas, então aí nós articulávamos quais eram as necessidades. [...] paralelamente a isso, a gente tinha um Comitê Gestor do Pacto, que era formado pela representante da Undime, pela representante da Secretaria de Educação, pelas coordenações geral e adjuntas do Pnaic Representante da UFPE 2).

${ }^{3}$ O SisPacto é o sistema de monitoramento do Pacto Nacional pela Alfabetização na Idade Certa disponibilizado no Simec. Disponível em: http://simec.mec.gov.br. 
Esses fragmentos são interessantes porque anunciam o tipo de vínculo entre a equipe técnica do Pnaic a nível nacional, as IFES e entidades sociais. De acordo com a proposta de pactuação, de cooperação, essa parceria com entidades sociais deveria chegar aos estados e municípios, dado o Art. 10 da Portaria $n^{\circ}$ 867, em que a "UNDIME deve prezar pela mobilização e a proposição de soluções para temas estratégicos, no âmbito do estado" (BRASIL, 2012b). Após essa discussão ampla sobre a origem do Pnaic, passaremos a focar a sua implementação no Recife.

\section{Pnaic no Recife: analisando uma experiência}

Para situar o leitor, iniciamos trazendo alguns dados do município do Recife. O município dispõe de 320 unidades de ensino, que atendem a cerca de 90 mil estudantes. São 232 escolas de Ensino Fundamental - das quais cinco oferecem ensino integral -, 53 creches e 21 creches-escolas, além de 14 unidades de Tecnologia na Educação (Utecs), distribuídas pelas 6 Regiões Político-Administrativas (RPA), que contabilizam 94 bairros na cidade ${ }^{4}$. A capital de Pernambuco conta ainda com o atendimento de ensino profissionalizante e Educação de Jovens e Adultos (EJA).

O Recife aderiu ao Pnaic no ano de 2012 e suas preocupações com a alfabetização das crianças também estão registradas em outros documentos que revelam o compromisso do município com essa questão. O Plano Municipal de Educação de Recife (Pmer), com vigência de 2015 a 2025, é um exemplo desse compromisso. Composto por 20 metas, o plano "trata do conjunto da educação, [...], expressando uma política educacional para todos os níveis, bem como as etapas e modalidades de educação e de ensino" (RECIFE, 2015, p. 19).

Entre as suas metas, explicitamos duas que se aproximam do debate de alfabetizar as crianças até os 8 anos de idade. A meta 2 trata especificamente do atendimento ao Ensino Fundamental e se alinha aos objetivos do Pnaic na medida em que propõe metas para alfabetização das crianças e esforços para que os estudantes concluam esta etapa da escolarização.

Temos ainda no Pmer a meta 5, "Alfabetizar todas as crianças, no máximo, até o final do $3^{\circ}$ (terceiro) ano do ensino fundamental", que é idêntica à meta 5 do PNE (2014-2024) e guarda estreita relação com os objetivos do Pnaic, indicando assim que, de acordo com as metas

${ }^{4}$ Disponível em: http://www.portaldaeducacao.recife.pe.gov.br/. 
contidas no planejamento do Pmer, a rede municipal se mantém afinada às metas de âmbito nacional e se alinha na busca de solução aos problemas educacionais.

Há ainda no Pmer a indicação de projetos e programas que são destinados à área da leitura, escrita e matemática e à alfabetização de modo geral, como o Programa de Letramento do Recife (Proler/2014); Correção do fluxo escolar (2015); Jornada ampliada de aprendizagem (1995); Nas ondas da leitura (2015); Qualiescola I e II (2006) e Programa Lição de Vida/EJA (2009). Assim, além da adesão ao Pnaic, o município veio revelando, conforme proposto nesse Plano, uma preocupação com ações que busquem avançar os processos de alfabetização das crianças e jovens. Ou seja, a política municipal caminha em articulação com a política proposta pela União, na medida em o município abrange um conjunto de projetos e programas como acima destacados.

Assim, na continuidade, buscamos diferenciar e esclarecer a consolidação das parcerias e colaborações no Pnaic considerando, como nos explica Raic (2009, p. 92), que "os documentos oficiais não trazem em seu texto como deve acontecer essa colaboração" e que cabe aos entes federados a sua devida regulamentação. Nesse caso, vale a pergunta: o que se entende por regime de colaboração? Como esse processo acontece na prática?

Como já destacamos, a principal linha de ação do Pacto é o processo de formação de professores. O município faz adesão e inicia o processo de organização e inserção dos professores alfabetizadores e organiza a definição operacional para viabilizar o processo formativo.

Uma das principais obrigações dos municípios e estados, descrita igualmente nos Artigos 13 e 14, da Portaria n ${ }^{\circ}$ 867/2012, é de garantir a participação dos alfabetizadores nas formações, "Fomentar e garantir a participação dos alfabetizadores de sua rede de ensino nas atividades de formação, [...] custeando o deslocamento e a hospedagem, sempre que necessário" (BRASIL, 2012b). A Representante local, sobre a escolha do dia de formação, informa que:

Tinha de outro jeito, mas o próprio MEC, nas primeiras palestras que ele foi dando, ele sinalizou para o sábado, para não comprometer o dia letivo. É claro que a rede poderia ter abraçado e ter dito: não, eu vou fazer de acordo com minha realidade, ele teria essa autonomia, mas 2013 foi um ano muito atípico, não é? Foi um ano de mudança de gestão, foi um ano político, de adesão, a adesão foi em 2012, em 2013 a gente estava com uma nova gestão na rede, entendeu? Foi um ano bem conturbado (Representante local 1).

Como vimos, não foi uma idealização do município de Recife as formações serem aos sábados; ocorreu por orientações do MEC. Essa orientação dada pelo MEC facilitou em âmbito nacional para os municípios e estados em relação à necessidade de suprir a ausência dos 
alfabetizadores em sala, por conta da obrigatoriedade dos dias letivos dos estudantes. No entanto, essa estratégia sacrifica parte do tempo de descanso semanal dos professores alfabetizadores e orientadores de estudos.

As formações continuadas, obrigatórias para o primeiro ciclo de alfabetização e fora do horário do trabalho, aos sábados, apresentam-se como uma estratégia governamental para reduzir custos na contratação de professores substitutos. Principalmente porque os cursistas recebem bolsas de estudos. O que, de alguma maneira, acaba pressionando os professores a se alinharem a esse tipo de política. Os argumentos do município se restringiram à obrigação do professor alfabetizador em comparecer aos sábados (já que havia o recebimento de bolsas) e à dificuldade administrativa de substituir todos os professores de sala de aula caso a formação acontecesse no horário letivo. Vejamos as repercussões sobre isso:

Na verdade, o grande problema do Pnaic era [ser] aos sábados, apesar de ser remunerada, a remuneração não pesava tanto quanto o dia de sábado, teve gente que saiu por conta disso (Orientador de estudos).

Eles diziam porque como era um projeto que vocês estão recebendo uma bolsa, e aí se for tirar todos os professores de sala de aula vai ter que ter uma demanda muito grande de professores para substituir, entendeu? Só que, se for levado para o lado pedagógico, o professor tá fazendo algo que vai melhorar a sala de aula (Professora alfabetizadora 2).

A escolha do dia de formação pesou sobre os professores nos anos posteriores a 2013 no que diz respeito a permanência no Pnaic, como bem explicou o Orientador de estudos de Recife que estava no Programa no momento da pesquisa. Aqui vemos um tipo de entrave que é comum em programas de formação continuada. Os governos municipais nem sempre conseguem resolver a questão da saída do professor de sala de aula a fim de participar dos momentos de formação. Nesses casos, a parte mais difícil fica para os professores que têm de trabalhar em jornada ampliada aos sábados. Jornada ampliada aqui é entendida no sentido de que a formação continuada do Pnaic é em função das atividades docentes.

Outro ponto interessante da análise no processo de implementação do Pnaic está ligado ao seu objetivo maior, que se reverbera no chão da escola. Assim, tomando a Portaria $n^{\circ}$ 867/2012, no Art. 10, inciso I, observamos que a coordenação municipal do Programa no Recife se incumbiu com a "mobilização da comunidade escolar, dos Conselhos de Educação e da sociedade local em torno das ações do Pacto" (BRASIL, 2012b). Como se vê, há a necessidade de mobilização da comunidade, ou seja, há um incentivo para um movimento em torno desse programa no sentido de ajudar a colocá-lo em ação na comunidade escolar. 
Nesse sentido, entendemos que as ações do Pnaic, além de envolverem os membros da cadeia de formação, devem propor "uma articulação com todos os envolvidos da escola" (Representante do MEC 1). Em entrevista, essa entrevistada indicou precisamente os destinos das ações do Pnaic: “o aprendizado é lá na ponta. Quando chega lá na ponta, é preciso entender que o direito de aprender até os oito anos não é responsabilidade só do professor que está lá, mas da escola como um todo. Daí a necessidade de um envolvimento amplo" (Representante do MEC 1). Ou seja, é na escola que se materializam as ações do Pnaic, é lá que elas devem tomar forma. Assim, vários elementos são importantes para o sucesso dessas ações. Um desses é de responsabilidade do MEC, nesse processo de pactuação: a distribuição de materiais didáticos. A normatização e proposta desse Programa revelam a importância do material, já que há uma grande articulação entre o processo formativo, as atividades desenvolvidas em sala de aula e o material didático. Daí ser este um elemento que pode contribuir para o sucesso do Pnaic. Esse processo de entrega aconteceu com alguns problemas: "No primeiro ano, só chegou depois, a gente começou sem material didático, né? Acho que pelo menos no primeiro mês, mas depois chegou" (Professora alfabetizadora 2).

Além dos atrasos do MEC no envio dos materiais utilizados pelos alfabetizadores de Recife, há também registro de má utilização pelas próprias escolas. Relatos de que o material, ao chegar às escolas, era organizado de tal maneira que impedia os professores de utilizá-lo, assim muitas vezes ficava guardado.

Eles [os materiais] chegaram no almoxarifado da escola, a caixa lacrada do jogo de alfabetização, ou então os pacotes do PNLD de livros lindos, maravilhosos, numa caixa fechada na sala da diretora porque ela disse que não podia estragar (Representante do MEC 1).

Então, como se pode ver no depoimento, havia pouco esclarecimento por parte de alguns diretores ou falta de envolvimento da comunidade escolar no processo de implementação do Programa. Como se sabe, nas escolas grandes, parte dos materiais didáticos são organizados e administrados pela gestão escolar, que até 2015 não participava das formações do Pnaic. Essa ausência de "parceria" entre os alfabetizadores de Recife e a gestão escolar na administração dos materiais didáticos é reflexo do baixo envolvimento da comunidade escolar (inclusive dos gestores escolares) na condução das ações do Pnaic.

A gente [orientador] trabalhava focando no professor, a gente não estava tão focado na escola. [...]. O Pnaic não projetou a escola, projetou aquelas turmas, é muito difícil trabalhar assim [...]. Não era a escola toda (Orientador de estudos). 
O foco das ações de formação, na medida em que incidiu nos professores alfabetizadores, favoreceu esse tipo de desarticulação entre estes e os demais segmentos da comunidade escolar. No caso de Recife, isso ficou evidente, pois, além de problemas com uso dos materiais didáticos, havia também dificuldades nas relações entre gestão escolar, coordenação pedagógica e alfabetizadores para a troca de experiências sobre o Pnaic nas escolas. Vejamos um depoimento: "Se não for a colega de escola para conversar, ninguém vem olhar o nosso trabalho. Se o professor não se colocar, como o pessoal da escola fica sabendo desse Pnaic? Como aproveitar o conteúdo mesmo?” (Professora alfabetizadora 1).

Um elemento importante que o MEC sugeriu para auxiliar no desenvolvimento das ações do Pnaic nas escolas foi o Núcleo de Alfabetização ${ }^{5}$, mas essa estratégia não se estruturou nas escolas.

Uma alfabetizadora relata sobre o acompanhamento da coordenação do Pnaic nas escolas: "Não [sobre visitas as escolas], a gente tem uma inspeção, uma técnica pedagógica, mas que trata dos assuntos pedagógicos da rede mesmo, nada tem a ver com o Pnaic" (Professora alfabetizadora 2). Dessa forma, verificamos que o movimento no interior das escolas foi marcado por certa desarticulação e pouca interação entre os membros da comunidade escolar, além de pouca interação entre a coordenação local do Pnaic em Recife e a comunidade escolar.

E de que maneira a equipe local fazia o acompanhamento na implementação do Pnaic em Recife? "Tinha a formação né? Tinha a frequência que a gente acompanhava e tinha o acompanhamento do trabalho do orientador, [já] que o orientador fazia a cobrança do professor, né?" (Representante local 1).

Se entendermos a escola como o local de implementação da política pública ou "como uma unidade administrativa a quem cabe colocar em ação políticas no nível do poder central” (AZEVEDO, 2002, p. 56), o acompanhamento - que estava previsto na legislação do Pnaic, mas foi ausente - pode revelar as dificuldades de colocar em prática um programa de grande envergadura como esse que estamos analisando, em decorrência dessa ausência de proximidade entre a proposta do poder central e a aplicação no local. Ou seja, nos documentos e nas orientações do MEC para implementação do Pnaic, encontramos diversos elementos que visaram ao sucesso das ações, mas nem sempre acontece como esperado. Há um movimento

${ }^{5}$ O MEC sugere a criação de um Conselho ou um Núcleo de Alfabetização, por meio do manual do Pnaic (2012a, p. 03), que se responsabilize e discuta as políticas da rede de ensino destinadas ao atendimento das crianças dos anos iniciais. As equipes das escolas devem definir planos de ação por unidade escolar e coordenar o trabalho coletivo, no universo dessas unidades. Para a articulação entre estas duas instâncias, verificar maiores detalhes sobre a formação dos Núcleos de Alfabetização. 
entre o proposto e o executado, próprio das ações que envolvem diferentes instâncias administrativas e que requerem diferentes níveis de colaboração.

No processo de colaboração, a responsabilidade municipal estava vinculada ao oferecimento de condições para a execução do processo formativo e de condições para seus professores participarem das formações. Assim, a Secretaria de Educação se responsabilizou pelo deslocamento, alimentação e acomodação de professores alfabetizadores e orientadores de estudos nos locais de formação.

Entre algumas das obrigações do MEC, estava o fornecimento de bolsas de estudos, pela Resolução no 4, de 27 de março de 2013, Art. 7, inciso I, alínea f: “conceder bolsas de estudo e pesquisa aos formadores, supervisores e coordenadores da Formação Continuada de Professores Alfabetizadores junto às IES". Por meio do Fundo Nacional de Desenvolvimento da Educação (FNDE), os recursos eram liberados e destinados aos pagamentos das bolsas aos professores e orientadores de estudos. Ao mesmo tempo, o MEC instituiu um processo de monitoramento via SisPacto que permitia, entre outras questões, liberar o pagamento das bolsas:

Para gente receber a bolsa mensal, tinha que ser enviado tudo que ela pedia para nós. E aí, eu acho que é um dos grandes impasses (Professora alfabetizadora 1).

Essas bolsas têm um prazo para serem liberadas no sistema. Não necessariamente chegar no banco. Então a gente quando cumpre esses prazos, o que acontece, às vezes, gera um prazo maior de uma pessoa para outra: já passou o prazo de liberação de bolsas, e a pessoa entregou as atividades com atraso. Então ela vai ter a bolsa liberada mais para frente (Representante do MEC 2).

As bolsas, consideradas como auxílio, traduziram-se na implementação como objetos de regulação para o cumprimento dos critérios do Programa, que deveria ser registrado no SisPacto. Isso atingia tanto os municípios como os próprios participantes individualmente. Para as representantes da UFPE:

Aquele município que acumulou formação [e com isto não realizou as atividades do SisPacto e] também acumulou bolsa em atraso tinha, a única forma de, digamos assim de punição se é que é punição mais e, é como eu disse a gente poderia, eu poderia chegar lá, olha vocês tem que fazer, então tem, vocês tem que fazer assim, assim, assado porque eles tinha autonomia pra determinadas questões e isso tava posto também no acordo (Representante da UFPE 3).

O que a gente podia fazer era segurar as bolsas. Como as bolsas estavam vinculadas à realização das formações, se não teve formação, não tem como liberar a bolsa (Representante da UFPE 2). 
Entretanto, o desdobramento dessa correlação entre as obrigações do SisPacto e o recebimento das bolsas não se traduziu, exatamente, em atrativo para os professores alfabetizadores e orientadores de estudos permanecerem nas formações do Pnaic em Recife.

Para os orientadores de estudos: O grupo de orientadores era um grupo muito bom assim. Mesmo, às vezes, com bolsa atrasada eles nunca deixaram de ir, e a prefeitura dava uma ajuda de custo (Representante local 2).

Para os professores alfabetizadores: Aconteceu, como eu disse, que acumulou, tipo eu passava... Já cheguei a receber três bolsas de uma vez só. Então, nesses três meses eu continuei frequentando as aulas normalmente (Professora alfabetizadora 2).

Portanto, as bolsas financiadas pelo MEC atrasavam, e isso nem sempre desestimulou os professores e orientadores de estudos, mas, como sabemos, há sempre um interesse para o recebimento de bolsas, já que o salário do professor nem sempre é condizente com a profissão. As implicações das bolsas em Recife foram:

É muito gratificante você perceber o interesse das pessoas estarem ali, e não é pela bolsa, porque é pouco. Mas é pela formação. Depoimento de gente dizendo assim: eu estou tendo... eu não estou tendo formação continuada, essa é a minha formação. Então assim... belíssimos os depoimentos (Representante da UFPE 3).

Atrasava [a bolsa] e, assim, eu não me importei, né? Tinha gente que tava contando com aquele dinheiro ali, naquela data, mas eu, no meu caso, não, eu achei até bom porque pegava uma soma maior (Professora alfabetizadora 2).

Analisando o caso das bolsas, foi possível inferir que o MEC também falhou na sua parte de cooperação com o Programa. Pois, mesmo que os professores e orientadores afirmem que a bolsa não era o principal elemento que os mantinha no Pnaic, temos clareza que a situação atual de baixos salários da classe dos professores indica que uma bolsa é sempre bem-vinda para reforçar os rendimentos mensais. Desse modo, a irregularidade do pagamento também gera constrangimentos à implementação do programa.

\section{Considerações finais}

Ao trabalhar com o Pnaic, nosso interesse se voltou para o entendimento do regime de colaboração. Como foi possível observar, esse programa, elaborado pelo governo federal, prevê a colaboração das instâncias locais (municípios e estados) a fim de ser concretizado. 
Recife, o local escolhido como campo de pesquisa, revelou algumas situações que implicaram diretamente no contexto de adesão e execução da política. Alguns elementos que envolvem parceria e colaboração acabam por ser fragilizados. Exemplos disso repousam nas decisões de acompanhamento das escolas, na fragilidade da equipe local, no atraso de pagamento de bolsas. Ou seja, a colaboração, prevista nos documentos que normatizam o Pnaic, não é algo fácil de colocar em prática. Como se sabe, não há uma definição clara na nossa legislação sobre os processos de colaboração intergovernamental. Há ainda a necessidade do seu fortalecimento.

Estabelecida a corresponsabilidade entre Estados, Municípios e União, o que se constata é a indefinição do que cabe a cada instância de poder, sobretudo quando se refere à constituição de instrumentos que explicitem os papéis específicos de cada esfera administrativa, assim como as ações que serão pactuadas entre os sistemas de educação com o fim de atingir o atendimento de toda a educação básica no âmbito municipal (ANDRADE, 2013, p. 02).

Programas como o Pnaic trazem na sua regulamentação as indicações de formas de cooperação intergovernamental, que ajudam a definir as responsabilidades de cada instância na execução da política. Mesmo assim, entendemos que nesse tipo de ação governamental o poder central dita as regras do jogo. O poder central aparece como o formulador da política e das decisões mais gerais sobre o seu desenvolvimento.

O que se percebe é que, em políticas como essa, as instâncias locais, por se constituírem como o lócus de execução, desdobram-se em estratégias para dar conta de suas responsabilidades e para suprir eventuais lacunas no processo de condução da política. De todo modo, concordamos que tais estratégias governamentais colaboram para a melhoria da educação básica no nosso país, atuando como um pacto nacional pela educação pública.

AGRADECIMENTOS: Agradecemos o apoio da Fundação de Amparo à Ciência e Tecnologia de Pernambuco (Facepe), que apoiou a pesquisa concedendo bolsa de estudos.

\section{REFERÊNCIAS}

ANDRADE, Edson. Regime de Colaboração no financiamento da Educação Básica no Brasil: a experiência dos fundos contábeis em foco. Educação, Santa Maria. v. 38, n. 2, maio/ago. 2013.

ANDRADE, Edson; GOMES, Alfredo. Estado federativo brasileiro. Implicações na gestão da educação. Revista Retratos da Escola, Brasília, v. 6, n. 10, p. 133-154, jan./jun. 2012. Disponível em: http//www.esforce.org.br. Acesso em: 23 maio 2017. 
AZEVEDO, Janete. Implicações da nova lógica de ação do estado para a educação municipal. Educ. Soc., Campinas, v. 23, n. 80, p. 49-71, set. 2002.

BARDIN, Laurence. Análise de conteúdo. Lisboa: Edições 70, 1989.

BRASIL. MEC. Lei $\mathbf{n}^{\mathbf{0}}$ 9.394, de 20 de dezembro de 1996. Estabelece as diretrizes e bases da educação nacional. Brasília, 1996. Disponível em:

http://www.planalto.gov.br/ccivil_03/leis/L9394.htm. Acesso em: 07 mar. 2019.

BRASIL. MEC. Manual do Pacto: Pacto pela Alfabetização na Idade Certa: o Brasil do futuro com o começo que ele merece. Brasília. DF, 2012a.

BRASIL. MEC. Portaria $n^{\circ} 867,4$ de julho de 2012. Institui o Pacto Nacional pela Alfabetização na Idade Certa [...]. Diário Oficial da União: seção 1, n. 129, Brasília, DF, 5 jul. 2012b. Disponível em:

http://download.inep.gov.br/educacao_basica/provinha_brasil/legislacao/2013/portaria_n867_ 4julho2012_provinha_brasil.pdf. Acesso em: 07 mar. 2019.

BRASIL. MEC. Lei no 13.005, de 25 de junho de 2014. Aprova o Plano Nacional de Educação - PNE e dá outras providências. 2014. Disponível em: http://www.planalto.gov.br/ccivil_03/_Ato2011-2014/2014/Lei/L13005.htm. Acesso em: 06 mar. 2019.

CUNHA, Maria; COSTA, Jean Mário Araújo; ARAÚJO, Rosimeire. Federalismo cooperativo brasileiro: implicações na gestão da educação municipal. Jornal de Políticas Educacionais, Paraná, n. 8, p. 14-23, jul./dez. de 2010. Disponível em:

https://revistas.ufpr.br/jpe/article/view/21828. Acesso em: 07 mar. 2019

DOWBOR, Ladislau. O que é Poder Local. São Paulo: Brasiliense, 2008.

OLIVEIRA, Adão Francisco de. Políticas públicas educacionais: conceito e contextualização numa perspectiva didática, 2012. In: OLIVEIRA, Francisco Adão de; PIZZIO, Alex; FRANÇA, George (Org.). Fronteiras da Educação: desigualdades, tecnologias e políticas. Goiás: Editora da PUC Goiás, 2010.

RAIC, Daniele. O sistema de ensino e o regime de colaboração: O dito e o por dizer um estudo de caso do município de Jequié - BA. 149f. Dissertação (Mestrado Educação). Programa de Pós-Graduação da Faculdade de Educação da Universidade Federal da Bahia. 2009.

RECIFE. Lei no 18.147/2015. Aprova o Plano Municipal de Educação. Diário Oficial do Município de Recife, 23 de jun. 2015.

SANTOS, Boaventura. A globalização e as ciências sociais. 2. ed. São Paulo: Cortez. 2002.

SANTOS, Natalia. Entre o proposto e o almejado: da proposta do Pacto Nacional pela Alfabetização na Idade Certa às expectativas almejadas por docentes participantes. 123f. Dissertação (Mestrado Gestão e Práticas Educacionais) - Universidade Nove de Julho, São Paulo, 2015. 


\section{Como referenciar este artigo}

NASCIMENTO, Jéssica Santos; SANTOS, Ana Lúcia Félix. Política pública e colaboração intergovernamental: analisando o caso do Pnaic em Recife. Revista on line de Política e Gestão Educacional, Araraquara, v. 23, n. 2, p. 370-387, maio/ago., 2019. E-ISSN:1519-9029. DOI: $10.22633 /$ rpge.v23i2.12385

Submetido em: 27/02/2019

Revisões requeridas: 10/03/2019

Aprovado em: 28/03/2019

Publicado em: 15/05/2019 